Check for updates

Cite this: RSC Adv., 2019, 9, 37778

\title{
Smart control of guest inclusion by $\alpha$-cyclodextrin using its hydration history $\dagger$
}

\author{
Askar K. Gatiatulin, (D) Viktoria Yu. Osel'skaya, Marat A. Ziganshin (1D \\ and Valery V. Gorbatchuk (D)*
}

Hydration history was found to control the inclusion capacity of $\alpha$-cyclodextrin (aCD) for volatile organic guests, so that its level may be switched from zero to the stoichiometric value and back by the variation of aCD hydration/dehydration order and direction. Such variation of the inclusion capacity is caused by the balance of two water roles: the activation of guest inclusion and guest/water competition. These observed concurrent roles and the cooperativity of guest inclusion and hydration make possible the smart tuning of the guest inclusion by the subtle change of preparation procedure. Depending on the hydration history, aCD was shown to form hydrates with the same water contents but different packing types and different kinetics of dehydration, which correlates with their different inclusion capacities for organic guests. This correlation reveals how the "high-energy" and "low-energy" water works in the guest inclusion by $\mathrm{aCD}$, which may be relevant for other cyclodextrins and hydrophilic receptors of biomimetic and biological natures. The results can help to rationalize the technologies of producing various inclusion compounds of cyclodextrins.

Received 23rd October 2019 Accepted 11th November 2019

DOI: 10.1039/c9ra08710a

rsc.li/rsc-advances calixarene polymorphs. The effect of hydration history on inclusion properties of cyclodextrins has not been studied previously.

The effect of CD hydration on inclusion properties is complicated even without the influence of its history. For inclusion of some alcohols by $\beta$-cyclodextrin (bCD), water is both an activating component and a competitor. ${ }^{8}$ These two roles of water may be relevant not only in the guest mixing with $\mathrm{CD}$, but also in the further non-equilibrium dynamic drying, where the ratio of $\mathrm{CD}$ : guest : water changes and the drying temperature and order are usually specified. ${ }^{25,26}$

In the present work, we studied the hydration history effect and its usage for control of $\alpha$-cyclodextrin inclusion properties. Being a prospective receptor for various applications, ${ }^{\mathbf{1} 27} \alpha$ cyclodextrin (aCD), Fig. 1, is much less used than bCD ${ }^{28}$ probably because of its much higher affinity for water. ${ }^{18}$ So, a more complicated optimization of inclusion conditions is needed for aCD to achieve a suitable inclusion capacity for organic guests, which is a relatively simple procedure for bCD. ${ }^{29,30}$

The hydration history effect on guest inclusion by aCD was studied in this work for the systems where guest is included from vapor phase by solid host in a batch system. Such systems do not require mechanical mixing of components and give more reproducible results because a corresponding sorption process gives the final state closer to an equilibrium one. ${ }^{31}$ Besides, the equilibration of solid host with guest vapor allows more control over thermodynamic activity of components in multicomponent systems to study the effect of host hydration on guest inclusion. ${ }^{\mathbf{8 , 3 2}}$
A. M. Butlerov Institute of Chemistry, Kazan Federal University, 18 Kremlyovskaya Str., Kazan 420008, Russia. E-mail: Valery.Gorbatchuk@kpfu.ru

$\dagger$ Electronic supplementary information (ESI) available: Data of TG/DSC/MS and TG/MS experiments, data of thermokinetic analysis, powder diffractograms. See DOI: $10.1039 / \mathrm{c} 9 \mathrm{ra} 08710 \mathrm{a}$ 


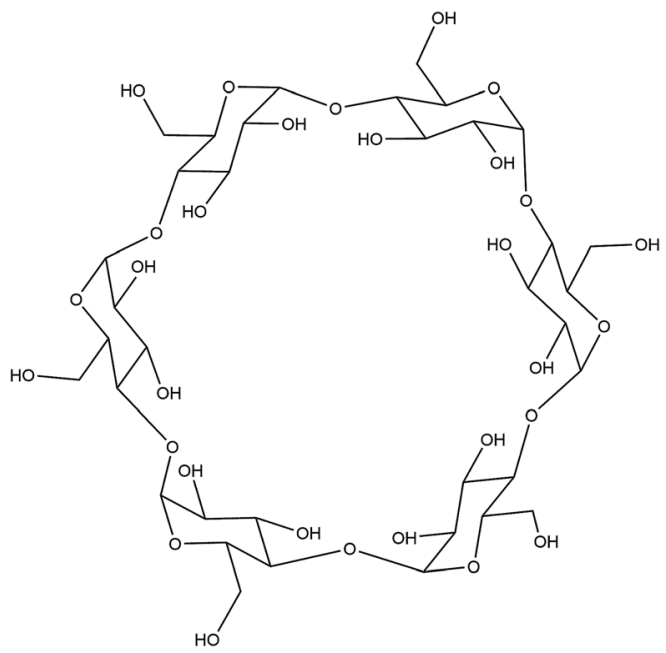

Fig. 1 Structure of $\alpha$-cyclodextrin (aCD).

In the present work, the optimal aCD hydration $(4: 1)$ for a study of hydration history effect was estimated in the inclusion processes shown in Fig. 2: (1) with simultaneous sorption of organic guest and water vapor by initially dry aCD, (2) guest inclusion performed simultaneously with dehydration of initially saturated aCD hexahydrate by a desiccant additive, and (3) saturation of aCD hexahydrate with guest vapor. In addition, the guest/water ratio in aCD phase was varied in the measurement of guest sorption isotherms on prehydrated aCD to reveal the influence of this ratio on the guest inclusion capacity.

To find how hydration history controls guest inclusion directly, the inclusion of organic compounds was studied for two tetrahydrates of aCD prepared by different ways: (1) by partial hydration of the dry host, and (2) by partial thermal dehydration of its saturated hexahydrate, Fig. 2. In these experiments, the possibility was revealed to switch the inclusion capacity of aCD without its dissolution or contact with liquid: just by change of its hydration order and conditions. The results were compared with inclusion properties of dried aCD

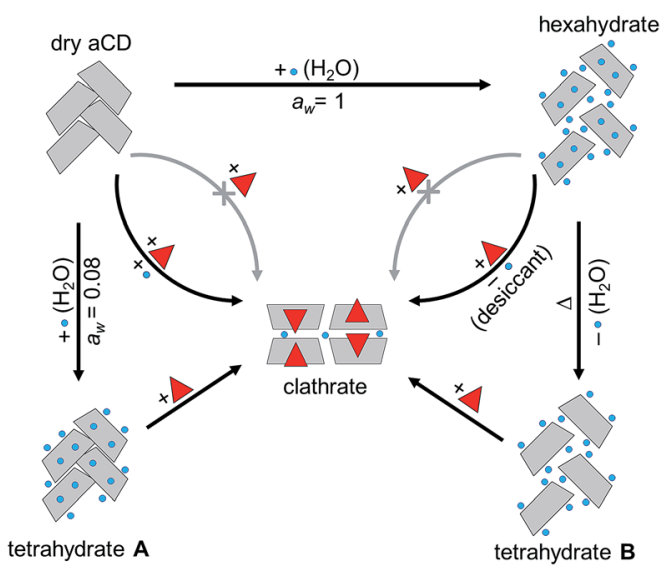

Fig. 2 Scheme of guest inclusion by aCD with different hydrations and hydration histories. determined elsewhere. ${ }^{18}$ To reveal the influence of the hydration history on aCD hydration state and the role of so-called "highenergy" and "low-energy" water in aCD inclusion properties, the effect of this history was studied in the present work on the packing of aCD hydrates and inclusion compounds and on the kinetics of water and guest release from these substances. These experiments are important for development of preparation methods for inclusion compounds of cyclodextrins and for comprehension of similar history effects on receptor properties of proteins.

\section{Experimental section}

\section{Materials}

$\alpha$-Cyclodextrin (aCD), Sigma-Aldrich, cat. no. 28705, was dried at $100{ }^{\circ} \mathrm{C}$ for $8 \mathrm{~h}$ in vacuum of $100 \mathrm{~Pa}$ before experiments. In dried aCD, a hydration level less than $1 \%$ wt. and an absence of volatile guests were shown by thermogravimetry with massspectrometry of evolved vapors. Organic guests were dried using $3 \AA$ molecular sieves. The purity of guests checked by GC was at least $99.5 \%$.

\section{Sample preparation}

For thermal analysis with mass-spectrometry of evolved vapors (TG/MS) and powder X-ray diffraction (PXRD) studies, samples of initial aCD hydrates (30-40 mg) were equilibrated with guest vapors in sealed $15 \mathrm{~mL}$ vials for $72 \mathrm{~h}$. In these vials, an excess of liquid organic sorbate $(100 \mu \mathrm{L})$ was placed in a glass insert to avoid the liquid-solid phase contact with a host powder. Molecular sieves $3 \AA$ (Kermel, $\left.\mathrm{K}_{x} \mathrm{Na}_{(12-x)}\left[\left(\mathrm{AlO}_{2}\right)_{12}\left(\mathrm{SiO}_{2}\right)_{12}\right]\right)$ with mass of $60-70 \mathrm{mg}$ in each vial were added as a desiccant in corresponding "aCD hexahydrate + desiccant + guest" experiments. The equilibration period was at least 10 times more than required to reach the constant composition of saturation products within experimental errors.

Tetrahydrate A and aCD hexahydrate were prepared by saturation of anhydrous aCD with aqueous vapors for 7 days as described elsewhere. ${ }^{18}$ For hexahydrate, the liquid water was added to the host sample in a $5 \%$ excess as written above. Tetrahydrate A was formed by equilibration with the vapor of the saturated aqueous solution of $\mathrm{KOH}$ having the relative humidity of $8 \%$. Tetrahydrate B was prepared by heating aCD hexahydrate in an open Petri dish at $65{ }^{\circ} \mathrm{C}$ in oven for 20 minutes. The water contents in $\mathrm{B}$ was determined by gravimetric method.

\section{Simultaneous thermogravimetry and differential scanning calorimetry with mass-spectrometry of evolved vapors (TG/ DSC/MS)}

TG/DSC/MS and TG/MS experiments were performed using STA 449 C Jupiter (Netzsch) device coupled with quadrupole massspectrometer QMS $403 \mathrm{C}$ Aeolos as described elsewhere. ${ }^{33}$ In thermal analysis, the sample was scanned with a rate of 10 $\mathrm{K} \mathrm{min}^{-1}$ up to $250{ }^{\circ} \mathrm{C}$, which followed by isothermal mode of heating at this temperature for $20 \mathrm{~min}$ and further heating with the same rate to $280^{\circ} \mathrm{C}$. In this experiment, a continuous purge 
with argon of $75 \mathrm{~mL} \min ^{-1}$ was used. The hydration of aCD hydrates was estimated with an error of $0.1 \mathrm{~mol} \mathrm{~mol}^{-1}(\mathrm{~mol}$ water per mol aCD). The hydration of ternary clathrates was determined with an error of $0.5 \mathrm{~mol} \mathrm{~mol}^{-1}$. The error of organic guest contents determination was $0.1 \mathrm{~mol} \mathrm{~mol}^{-1}$ for binary clathrates and $0.2 \mathrm{~mol} \mathrm{~mol}^{-1}$ for ternary clathrates. For simultaneous release of two and more guests, the additional calibration of MS sensor was used.

For determination of kinetic parameters, TG curves were measured for the samples of aCD hydrates and inclusion compounds with organic guest heated to $260{ }^{\circ} \mathrm{C}$ at different rates of 5,10 and $20 \mathrm{~K} \mathrm{~min}^{-1}$. The obtained TG data were processed using NETZSCH Thermokinetics 3.1 software. Two "model-free" methods of Friedman ${ }^{34}$ and Ozawa-Flynn-Wall ${ }^{35,36}$ were used for approximation of the experimental data according to the recommendation of International Confederation for Thermal Analysis and Calorimetry (ICTAC), ${ }^{37}$ which requires to use at least two such methods. Besides, the experimental data were approximated by model methods available in the used software, and the best method was selected by the highest correlation coefficient.

\section{Static method of headspace GC analysis (HSGC)}

HSGC method was used to determine vapor sorption isotherms of organic guests as described elsewhere ${ }^{38}$ For determination of sorption isotherms on tetrahydrate A by HSGC method, the sample preparation was the same as for TG/MS, but the added amount of guest liquid was varied so that the guest was completely evaporated in equilibration for 72 hours at $298 \mathrm{~K}$. For simultaneous sorption of guest and water, dried aCD samples were equilibrated with different amounts of liquid guest + water mixture having a constant water/guest molar ratio $17: 1$. This ratio was chosen for a guest to reach a relatively high activity (relative vapor pressure) $P / P_{0}$ but below 0.8 at maximal possible aCD hydration and complete evaporation of the added liquids at equilibrium. In this experiment, the value of aCD hydration $h$ was calculated by the amount of added water in mol per $1 \mathrm{~mol}$ aCD. The aCD hydration degree $h / h_{\max }$ was calculated as fraction of maximal aCD hydration value $h_{\max }=6$.

By HSGC method, a relative vapor pressure (thermodynamic activity) of an organic guest in the studied systems, $P / P_{0}$, was determined, where $P$ is a partial vapor pressure of the guest and $P_{0}$ is its saturated vapor pressure. The guest uptake $A$ (mol of guest per 1 mole of aCD) was determined as a difference between an initial amount of guest added and its contents in vapor phase calculated from a value of $P / P_{0}$ and vapor volume. The error of $P / P_{0}$ determination was $5 \%$ and no less than 0.01 . Guest uptake $A$ was determined with an error of $5 \%$ but no less than $0.1 \mathrm{~mol}$ per $1 \mathrm{~mol}$ of aCD. Each isotherm was determined at least twice with fresh samples of aCD.

\section{Powder X-ray diffraction (PXRD)}

Powder X-ray diffractograms were determined using a Rigaku MiniFlex 600 diffractometer equipped with a D/teX Ultra detector. In this experiment, $\mathrm{Cu} \mathrm{K} \alpha$ radiation $(30 \mathrm{kV}, 10 \mathrm{~mA})$ was used, $\mathrm{K} \beta$ radiation was eliminated with $\mathrm{Ni}$ filter. The diffractograms were determined at room temperature in the reflection mode, with scanning speed of $5^{\circ} \mathrm{min}^{-1}$. Clathrate samples were loaded into a glass holder. Patterns were recorded in the $2 \theta$ range from $3^{\circ}$ to $50^{\circ}$ without sample rotation.

\section{Results and discussion}

To study the hydration effect on aCD inclusion properties, aCD saturated hydrate $\left(\mathrm{aCD} \cdot 5.9 \mathrm{H}_{2} \mathrm{O}\right)^{18}$ was equilibrated with vapors of such organic guests as methanol, ethanol, 1-propanol, acetone, benzene, nitromethane, propionitrile, dichloromethane, chloroform.

Products prepared in "aCD hexahydrate + guest vapor" system were studied using a combined TG/MS, corresponding
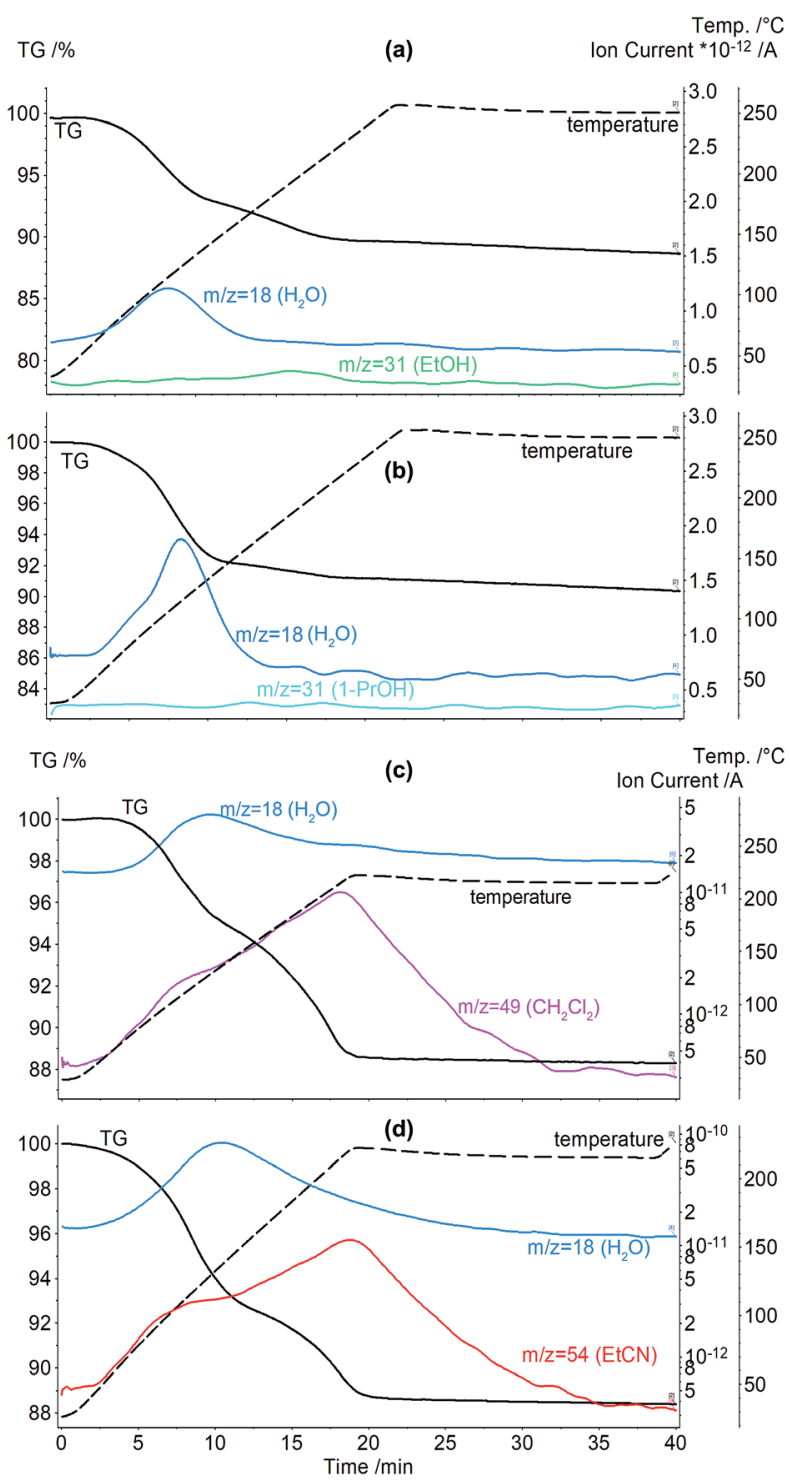

Fig. 3 Curves of TG/MS analysis for clathrates prepared by saturation of aCD hexahydrate with guest vapors in the absence of desiccant (a) $\mathrm{aCD} \cdot 1.0 \mathrm{EtOH} \cdot 3.5 \mathrm{H}_{2} \mathrm{O}$ and (b) $\mathrm{aCD} \cdot 0.3 n-\mathrm{C}_{3} \mathrm{H}_{7} \mathrm{OH} \cdot 5 \mathrm{H}_{2} \mathrm{O}$; and in the presence of desiccant (c) $\mathrm{aCD} \cdot 1.0 \mathrm{CH}_{2} \mathrm{Cl}_{2} \cdot 2.0 \mathrm{H}_{2} \mathrm{O}$ and (d) $\mathrm{aCD} \cdot 1.1 \mathrm{EtCN} \cdot 3.6 \mathrm{H}_{2} \mathrm{O}$. 
curves of thermal analysis are given in Fig. $3 \mathrm{a}$ and $\mathrm{b}$ and ESI. $\dagger$ From these curves, total mass loss corresponding to guest release $\Delta m$, clathrate compositions calculated from TG/MS data and peak points $T_{\max }$ on MS curves of organic guest release were determined. These parameters are given in Table 1 for clathrates with organic guest contents higher than $0.1 \mathrm{~mol}$ per mol aCD. Benzene, nitromethane, propionitrile, dichloromethane and chloroform are not included above this level.

The data of TG/MS, Fig. 3a, b and Table 1, show that aCD hexahydrate is able to include above 1 mole per mole of aCD only such small and hydrophilic molecules as methanol and ethanol. 1-Propanol and acetone are included in small quantities: 0.3 and $0.2 \mathrm{~mol}$ per mol aCD, respectively, Table 1 . The other studied guests are included in amounts less than $0.1 \mathrm{~mol}$ per mol aCD and do not change the water contents in aCD phase. Such inclusion properties are much poorer than for anhydrous aCD, which includes $3.3 \mathrm{~mol} \mathrm{CH}_{3} \mathrm{OH}, 2.2 \mathrm{~mol}$ $\mathrm{C}_{2} \mathrm{H}_{5} \mathrm{OH}, 1.8 \mathrm{~mol} \mathrm{CH}_{3} \mathrm{NO}_{2}, 1.0 \mathrm{~mol} n-\mathrm{C}_{3} \mathrm{H}_{7} \mathrm{OH}, 0.6 \mathrm{~mol}$ $\left(\mathrm{CH}_{3}\right)_{2} \mathrm{CO}, 0.4 \mathrm{~mol} \mathrm{C}_{2} \mathrm{H}_{5} \mathrm{CN}$ per mol aCD and has no inclusion affinity for dichloromethane. ${ }^{18}$ This behavior of aCD is also significantly different from bCD, which when hydrated is able to include such hydrophobic guests as benzene, chloroform, and also hydrophilic acetone in amounts more than $1 \mathrm{~mol}$ per mol of host. $^{8}$

The observed lower inclusion capacity of aCD hexahydrate than that of saturated bCD hydrate is probably caused by much higher affinity of aCD for water, which should be replaced by an included guest. The value of aCD hydration Gibbs energy is $\Delta G_{\mathrm{c}}$ $=-6.8 \mathrm{~kJ}$ per mol of water. ${ }^{18}$ For comparison, from 3-5 water molecules usually exchanged for included guest in saturated hydrate of bCD, the first 3 molecules have this value of only $-0.1 \mathrm{~kJ} \mathrm{~mol}^{-1}$, while for the other this parameter is equal to $\Delta G_{\mathrm{c}}$ $=-3.3 \mathrm{~kJ} \mathrm{~mol}^{-1} \cdot{ }^{19} \mathrm{So}$, a much higher moving force of organic guest inclusion is needed to compensate the partial dehydration of aCD than this can be expected for bCD.

The competition of water and organic guest for inclusion by aCD implies a possibility to shift this equilibrium in favor of

Table 1 Data of TG/MS analysis for clathrates prepared by saturation of $\mathrm{aCD}$ hexahydrate

\begin{tabular}{llll}
\hline Guest & Inclusion compound & & \\
\hline \multicolumn{2}{l}{ Inclusion system: aCD $\cdot \mathbf{5 . 9 \mathbf { H } _ { 2 } \mathrm { O } + \text { guest }}$} & $\Delta m / \%$ & $T_{\max }{ }^{b} /{ }^{\circ} \mathrm{C}$ \\
$\mathrm{CH}_{3} \mathrm{OH}$ & $\mathrm{aCD} \cdot 2.2 \mathrm{CH}_{3} \mathrm{OH} \cdot 2.3 \mathrm{H}_{2} \mathrm{O}$ & 10.2 & 124 \\
$\mathrm{C}_{2} \mathrm{H}_{5} \mathrm{OH}$ & $\mathrm{aCD} \cdot 1.0 \mathrm{C}_{2} \mathrm{H}_{5} \mathrm{OH} \cdot 3.5 \mathrm{H}_{2} \mathrm{O}$ & 10.0 & 191 \\
$n-\mathrm{C}_{3} \mathrm{H}_{7} \mathrm{OH}$ & $\mathrm{aCD} \cdot 0.3 n-\mathrm{C}_{3} \mathrm{H}+\mathrm{OH} \cdot 5 \mathrm{H}_{2} \mathrm{O}$ & 8.8 & 190 \\
$\left(\mathrm{CH}_{3}\right)_{2} \mathrm{CO}$ & $\mathrm{aCD} \cdot 0.2\left(\mathrm{CH}_{3}\right)_{2} \mathrm{CO} \cdot 3.5 \mathrm{H}_{2} \mathrm{O}$ & 9.4 & 164
\end{tabular}

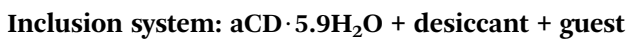

$\begin{array}{llll}\mathrm{CH}_{2} \mathrm{Cl}_{2} & \mathrm{aCD} \cdot 1.0 \mathrm{CH}_{2} \mathrm{Cl}_{2} \cdot 2.0 \mathrm{H}_{2} \mathrm{O} & 11.5 & 215 \\ \mathrm{CH}_{3} \mathrm{NO}_{2} & \mathrm{aCD} \cdot 1.0 \mathrm{CH}_{3} \mathrm{NO}_{2} \cdot 3.0 \mathrm{H}_{2} \mathrm{O} & 10.6 & 187 \\ \mathrm{C}_{2} \mathrm{H}_{5} \mathrm{CN} & \mathrm{aCD} \cdot 1.1 \mathrm{C}_{2} \mathrm{H}_{5} \mathrm{CN} \cdot 3.6 \mathrm{H}_{2} \mathrm{O} & 11.4 & 220 \\ n-\mathrm{C}_{3} \mathrm{H}_{7} \mathrm{OH} & \mathrm{aCD} \cdot 1.1 n-\mathrm{C}_{3} \mathrm{H}_{7} \mathrm{OH} \cdot 3.0 \mathrm{H}_{2} \mathrm{O} & 10.7 & 215 \\ \left(\mathrm{CH}_{3}\right)_{2} \mathrm{CO} & \mathrm{aCD} \cdot 1.3\left(\mathrm{CH}_{3}\right)_{2} \mathrm{CO} \cdot 2.7 \mathrm{H}_{2} \mathrm{O} & 11.4 & 101 ; 152\end{array}$

${ }^{a}$ Clathrate composition is determined from TG/MS data. ${ }^{b} T_{\max }$ is a peak point of organic guest release on its MS curve. The error of water contents determination in ternary clathrates is $\pm 0.6 \mathrm{~mol}$ per mol aCD. organic guest by a decrease of aCD hydration using desiccant simultaneously with guest inclusion. This possibility was investigated by determination of $\mathrm{aCD} \cdot 5.9 \mathrm{H}_{2} \mathrm{O}$ inclusion capacity for various organic guests in the presence of molecular sieves $3 \AA$ by TG/MS method. The guests studied are acetone, 1propanol, propionitrile, dichloromethane and nitromethane, which have the smallest molecular size among the liquid compounds not included in significant amounts (above $0.3 \mathrm{~mol}$ per $1 \mathrm{~mol}$ of host) by aCD hexahydrate without desiccant. The TG/MS data for the clathrates prepared in "aCD $5.9 \mathrm{H}_{2} \mathrm{O}+$ desiccant + guest" system are given in Fig. 3c, d and Table 1, including clathrate composition, mass loss at heating $\Delta m$ and peak points $T_{\max }$ on MS curves of organic guest release.

The addition of molecular sieves dramatically improves the observed inclusion capacity of initially saturated aCD hydrate, Table 1. All studied guests are included in amounts higher than $1 \mathrm{~mol}$ per mol aCD in the presence of this desiccant, while its absence for the same guests enables inclusion of no more than $0.3 \mathrm{~mol}$, Table 1 . So, the presence of desiccant in system with aCD hydrate and organic guest makes the water exchange for organic guests thermodynamically more favorable and creates a possibility to control the inclusion.

The observed role of water in receptor properties of aCD is more complex than a simple competition with organic guest in aCD, which can be seen in comparison of inclusion capacity of $\mathrm{aCD} \cdot 5.9 \mathrm{H}_{2} \mathrm{O}$ in the presence of desiccant and of anhydrous aCD in binary systems with the same guests. The contents of propionitrile and acetone included in "hexahydrate + desiccant + guest" system, Table 1 , are about 3 and 2 times higher, respectively, than in binary systems with anhydrous aCD. ${ }^{18}$ The saturation of this aCD hydrate in the presence of desiccant also allowed encapsulating the hydrophobic compound dichloromethane, Fig. $3 \mathrm{c}$ and Table 1, which cannot be included by dried aCD. ${ }^{18}$ So, water being a strong competitor for inclusion space in aCD still is necessary to activate the inclusion of organic guests by this hydrophilic host.

To study the activation of guest inclusion by aCD hydration and competition of organic guest and water in this process, the isotherm of simultaneous sorption of 1-propanol and water was determined using static method of headspace GC analysis, Fig. 4, where $A /\left(P / P_{0}\right)$ is the sorption affinity of aCD for guest plotted $v s$. the aCD hydration degree $h / h_{\max }$. This isotherm gives a two-dimensional presentation of hydration effect on guest sorption for three-component system where both guest and water contents in solid aCD phase are varied..$^{39}$ More detailed sorption data for this isotherm are given in ESI. $\uparrow$ 1-Propanol was chosen as the largest organic guest, which is included by anhydrous aCD from vapor phase. ${ }^{18}$ The isotherm was determined at the fixed guest/water molar ratio of $1: 17$ to have a minimal guest effect on aCD hydration.

The isotherm of simultaneous 1-propanol and water sorption on aCD, Fig. 4, has nearly the same bell-shaped form as the previously observed one for bCD. ${ }^{8}$ Still, there is a difference in the values of the host optimal hydration $h / h_{\max }$ for $1-\mathrm{PrOH}$ inclusion. The sorption affinity $A /\left(P / P_{0}\right)$ of aCD for this guest increases at the lower range of hydration degree $0<h / h_{\max }<$ 0.17 , which corresponds to the formation of aCD monohydrate, 


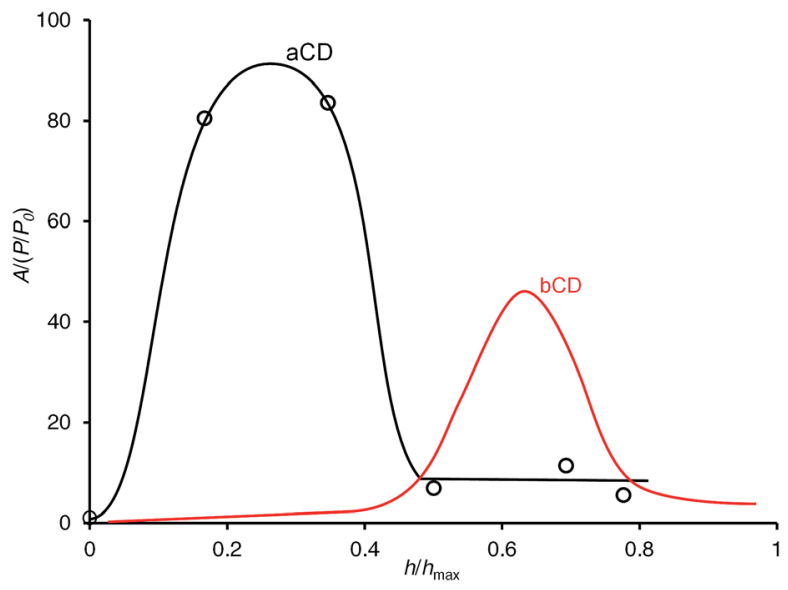

Fig. 4 Sorption isotherm of 1-propanol by initially anhydrous aCD and bCD for simultaneous sorption of guest and water at constant guest/ water molar ratio $1: 17 . T=298 \mathrm{~K}$. The lines are drawn to guide the eye. The bCD isotherm is from ref. 8 .

and decreases when the hydration degree $h / h_{\max }$ changes from 0.35 to 0.50 where the third water molecule is added to the host phase. In this fall of sorption affinity, the guest activity $\left(P / P_{0}=\right.$ 0.02) still remains far below saturation level, ESI. $\dagger$ For comparison, bCD has the maximal affinity $A /\left(P / P_{0}\right)$ for $1-\mathrm{PrOH}$ at much higher value of hydration degree $h / h_{\max }=0.65$ corresponding to bCD octahydrate. ${ }^{8}$ So, as well as for bCD, the hydration of aCD may have two opposite effects on guest inclusion: an activation at low water contents but competition with the guest at higher hydration levels.

Comparison of residual hydration of aCD clathrate with 1propanol prepared in "aCD $\cdot 5.9 \mathrm{H}_{2} \mathrm{O}+$ desiccant + guest" system, Table 1, with the optimal hydration at simultaneous sorption of 1-propanol and water on aCD, Fig. 4, shows that the high inclusion capacity in the first case is reached at the higher hydration. Such difference can be explained by the influence of hydration history: the hydration degree in these two experiments changes in opposite directions just in the process of clathrate formation.

To exclude the influence of the simultaneous hydration change at the guest inclusion, the inclusion properties of aCD with the fixed intermediate hydration were studied. For this, the aCD tetrahydrate (tetrahydrate A) was prepared by hydration of dry aCD as described above, with composition of aCD $\cdot 3.8 \mathrm{H}_{2} \mathrm{O}$ determined by TG. $^{18}$ The vapor sorption isotherms of dichloromethane, nitromethane, acetone, propionitrile and 1propanol on A were determined using static method of headspace GC analysis (HSGC), Fig. 5. For comparison, sorption isotherms of the same guests on anhydrous aCD determined earlier $^{18}$ are also shown in Fig. 5 with the exception of dichloromethane, which is not included by dry aCD.$^{18}$ The guest contents in inclusion compounds corresponding to the saturation parts of sorption isotherms are given in Table 2.

Comparison of sorption isotherms on tetrahydrate $\mathrm{A}$ and anhydrous aCD exhibits the activating role of water at low guest activities. For all guests studied, the characteristic guest activity

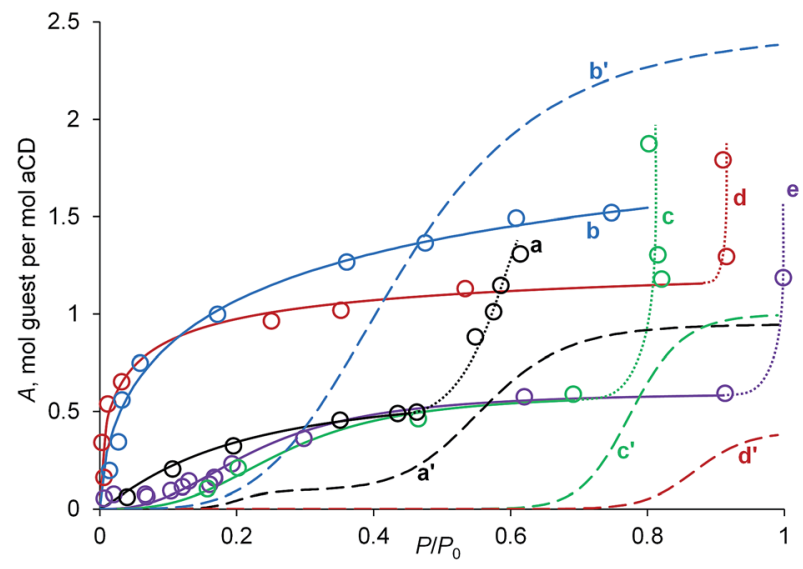

Fig. 5 Vapor sorption isotherms of (a) acetone, (b) nitromethane, (c) 1propanol, (d) propionitrile, (e) dichloromethane on aCD tetrahydrate A (solid lines) and $\left(a^{\prime}-d^{\prime}\right)$ on dry $a C D$ of the same guests, respectively, from ref. 18 (dashed lines). Lines are drawn to the guide of eye. Dotted lines correspond to a partial formation of guest-water solution.

$P / P_{0}=a_{0.5 \mathrm{~s}}$ at inclusion extent of $50 \%$ is lower for isotherms of aCD tetrahydrate, Fig. 5 . The most significant decrease of $a_{0.5 \mathrm{~s}}$ values is observed for propionitrile and nitromethane, which have this parameter equal to 0.01 and 0.04 , while for anhydrous aCD these $a_{0.55}$ values are much higher: 0.87 and 0.44 , respectively, Fig. 5.

The observed increase in the inclusion affinity of hydrated aCD removes or decreases much the apparent cooperativity of sigmoidal sorption isotherms for dry aCD, Fig. 5. So, the isotherms of propionitrile and nitromethane on tetrahydrate $\mathrm{A}$ have a shape close to that of Langmuir isotherms. For the other studied guests, the slope in inflection points of isotherms is lower for A than for dry aCD. This decrease of cooperativity is

Table 2 Data of TG/MS analysis for clathrates prepared by saturation of $\mathrm{aCD}$ tetrahydrates

\begin{tabular}{llrll}
\hline Guest & \multicolumn{1}{c}{ Inclusion compound } \\
\hline
\end{tabular}

Initial host state: tetrahydrate $\mathrm{B}$

$\begin{array}{llll}\mathrm{CH}_{2} \mathrm{Cl}_{2} \quad \mathrm{aCD} \cdot 0.3 \mathrm{CH}_{2} \mathrm{Cl}_{2} \cdot 4.0 \mathrm{H}_{2} \mathrm{O} & 8.7 & 170\end{array}$

$\mathrm{CH}_{3} \mathrm{NO}_{2} \quad \mathrm{aCD} \cdot 0.6 \mathrm{CH}_{3} \mathrm{NO}_{2} \cdot 4.5 \mathrm{H}_{2} \mathrm{O} \quad 10.6 \quad 113 ; 175$

$\mathrm{C}_{2} \mathrm{H}_{5} \mathrm{CN} \quad \mathrm{aCD} \cdot 1.0 \mathrm{C}_{2} \mathrm{H}_{5} \mathrm{CN} \cdot 4.1 \mathrm{H}_{2} \mathrm{O} \quad 11.7 \quad 199$

$n-\mathrm{C}_{3} \mathrm{H}_{7} \mathrm{OH} \quad \mathrm{aCD} \cdot 0.5 n-\mathrm{C}_{3} \mathrm{H}_{7} \mathrm{OH} \cdot 4.7 \mathrm{H}_{2} \mathrm{O} \quad 10.3 \quad 196$

$\left(\mathrm{CH}_{3}\right)_{2} \mathrm{CO} \quad \mathrm{aCD} \cdot 0.3\left(\mathrm{CH}_{3}\right)_{2} \mathrm{CO} \cdot 4.0 \mathrm{H}_{2} \mathrm{O} \quad 8.6 \quad 178$

${ }^{a}$ Clathrate composition calculated from TG/MS data; benzene is not included both by A and B, ESI. ${ }^{b} T_{\max }$ is a peak point of organic guest release on MS curves. ${ }^{c} S_{\mathrm{HSGC}}$ is guest contents in aCD clathrates corresponding to the saturation parts of sorption isotherms determined by HSGC with the guest activity $P / P_{0}$ given in brackets if below unity. The error of water contents determination in ternary clathrates by TG/MS method is $\pm 0.5 \mathrm{~mol}$ per mol aCD. 
linked to the increase of a number of components in the thermodynamic system, which increases the number of freedom degrees by Gibbs phase rule if water, organic guest and host form one solid phase of ternary inclusion compound.

The activating effect of aCD hydration observed in sorption isotherms of organic vapors, Fig. 4 and 5, is opposite to the competition between water and organic guests for inclusion by aCD revealed in the above comparison of inclusion capacities of saturated aCD hexahydrate, the same hydrate in the presence of desiccant, Table 1, and dry aCD. ${ }^{18}$ This may be a result of the different guest/host ratio in these experiments and varying ratio of these effects at different aCD hydrations.

The inclusion capacity of tetrahydrate A estimated by the saturation parts of sorption isotherms, Fig. 5 and Table 2, is the same as for aCD hexahydrate with desiccant for $\mathrm{CH}_{2} \mathrm{Cl}_{2}$, $\mathrm{CH}_{3} \mathrm{NO}_{2}$ and EtCN but much lower for acetone and 1-propanol, Table 1. The observed difference for the last two guests may be caused by the formation of separate aqueous solution of guest through partial aCD dehydration, which can be seen in cooperative increase of guest uptake at its activity $P / P_{0}$ near 0.5 for acetone and near 0.8 for 1-PrOH, Fig. 5 .

To find the inclusion capacity of tetrahydrate A under the same conditions as for "aCD $5.9 \mathrm{H}_{2} \mathrm{O}$ + desiccant + guest" system, the products of tetrahydrate A equilibration with the
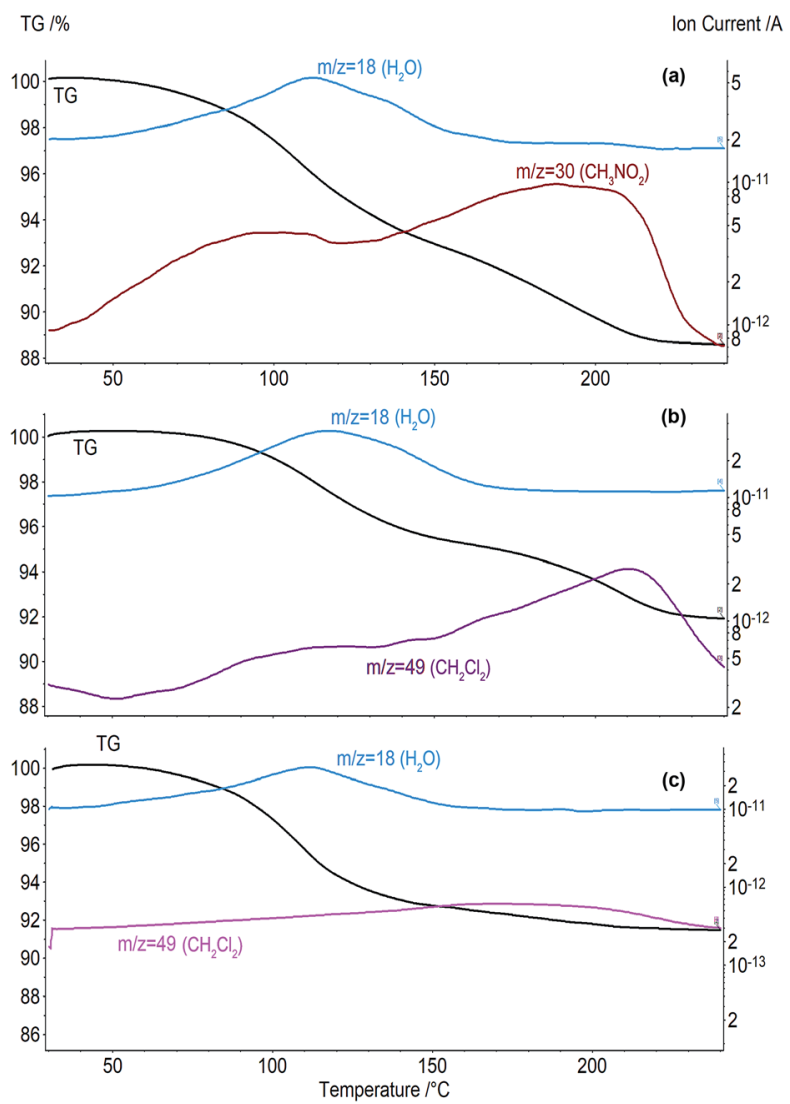

Fig. 6 Curves of TG/MS analysis for clathrates: (a) aCD $1.4 \mathrm{CH}_{3} \mathrm{NO}_{2} \cdot 2.0 \mathrm{H}_{2} \mathrm{O}$ and (b) aCD $0.4 \mathrm{CH}_{2} \mathrm{Cl}_{2} \cdot 3.0 \mathrm{H}_{2} \mathrm{O}$ prepared by saturation of tetrahydrate $\mathrm{A}$; (c) $\mathrm{aCD} \cdot 0.3 \mathrm{CH}_{2} \mathrm{Cl}_{2} \cdot 4.0 \mathrm{H}_{2} \mathrm{O}$ prepared by saturation of tetrahydrate $\mathrm{B}$. saturated vapor of guest taken in excess were studied by TG/MS method. The TG/MS curves determined are given in Fig. 6 and ESI. $\dagger$ The values of sample mass loss $\Delta m$, corresponding clathrate compositions calculated from TG/MS data and MS peak points $T_{\max }$ of guest release are given in Table 2 .

In average, the inclusion capacity of tetrahydrate A for the same guests, Table 2, is a little lower than in "aCD $5.9 \mathrm{H}_{2} \mathrm{O}+$ desiccant + guest" systems, Table 1 . The uptake of dichloromethane by tetrahydrate A is 2.5 times lower and the uptake of nitromethane is $40 \%$ higher than that in the systems with desiccant. The contents of the other guests studied in inclusion compounds are close in these two experiments and the difference does not exceed the experimental errors, Tables 1 and 2. The hydration values of inclusion compounds prepared with the same guests in these experiments with tetrahydrate $\mathrm{A}$ and 'aCD $5.9 \mathrm{H}_{2} \mathrm{O}+$ desiccant' are not much different. So, the observed difference of inclusion capacity for organic guests may be caused also by some other factor than hydration, e.g. by hydration history. Tetrahydrate A has an increasing hydration in its preparation with mostly small or no dehydration at guest inclusion, while the additive of desiccant to the hexahydrate gives a much higher dehydration of aCD in the inclusion process.

Each of the five types of inclusion experiments described above has a specific hydration history, which varies by direction of aCD hydration change and by the order of this change: before or simultaneously with the guest inclusion. To make the effect of this history more apparent, the inclusion properties of another tetrahydrate, B, were studied, which has the same composition as A but different direction of hydration change in its preparation. The tetrahydrate $\mathrm{B}$ with composition of aCD $\cdot 4.0 \mathrm{H}_{2} \mathrm{O}$ was prepared by partial dehydration of $\mathrm{aCD} \cdot 5.9 \mathrm{H}_{2} \mathrm{O}$. The products of tetrahydrate $\mathrm{B}$ equilibration with the saturated vapors of the same guests were studied by TG/MS method, and the results are given in Fig. 6 and Table 2, ESI. $\dagger$

The comparison of the inclusion properties of tetrahydrates A and B exhibits a significant effect of aCD hydration history. For the guests studied, the average inclusion capacity of tetrahydrate B is near half of this value for A, Table 3. Besides, this history has an effect on the number of water molecules exchanged for organic guest. Thus, tetrahydrate B does not lose water at the guest inclusion, while 2-3 molecules of water are exchanged in tetrahydrate $\mathrm{A}$ for dichloromethane, propionitrile and acetone, Table 2. Both tetrahydrates are unable to include benzene, like aCD $\cdot 5.9 \mathrm{H}_{2} \mathrm{O}$ or dry $\mathrm{aCD} .{ }^{18}$ So, the inclusion capacity of aCD hydrate may be increased or decreased twice by variation its hydration history. Such control can be called smart as it uses the switching the aCD hydration/dehydration order.

The average inclusion capacity for the same 5 organic guests, dichloromethane, nitromethane, propionitrile, 1-propanol and acetone, increases in the order: $\mathrm{aCD} \cdot 5.9 \mathrm{H}_{2} \mathrm{O}<\mathrm{B}<$ dry aCD $<\mathrm{A}<$ ' $\mathrm{aCD} \cdot 5.9 \mathrm{H}_{2} \mathrm{O}$ with desiccant'. So, water both interferes with guest inclusion by aCD and activates this process, and the ratio of these factors can be controlled through the hydration history: a prior partial and complete dehydration of saturated hydrate is favorable for guest inclusion, but more inclusion is reached by 
Table 3 Parameters of the aCD crystal packings and typical powder diffractograms

\begin{tabular}{lccc}
\hline Packing type & Cell volume, $\AA^{3}$ & Cell volume per $1 \mathrm{aCD}, \AA^{3}$ & Characteristic peaks $(2 \theta),^{\circ}$ \\
\hline Form I & 4792.97 (ref. 40$)$ & 1198.24 & $5.1,13.4,14.2,21.5$ \\
Form III & 5065.62 (ref. 41) & 1266.41 & $4.7,13.2,22.1$ \\
Form IIIa $^{a}$ & 3787.41 & 946.85 & $4.9,13.7,16.0$ \\
Columnar $^{a}$ The indexation data are given in ESI. & 2646.30 (ref. 45) & 1323.15 & $7.4,12.9,19.8$ \\
\end{tabular}

a preliminary partial hydration and especially by dehydration, which is simultaneous with guest inclusion. A similar effect of hydration history on the receptor properties of a hydrophilic material with flexible matrix was observed for enzymatic activity of cross-linked crystals of subtilisin. ${ }^{20}$

To find the structural causes of the observed dependence of aCD inclusion capacity on its hydration history, the packing patterns were determined using PXRD method for the studied initial hydrates and inclusion compounds prepared with the excessive guest amount and listed in Tables 1 and 2. The determined diffractograms are given in Fig. 7 and ESI. $\uparrow$ The observed characteristic peaks and corresponding main packing types and cell volumes according to the literature data ${ }^{40,41}$ and indexing in this work (ESI $\dagger$ ) are given in Table 3. The scheme of the observed changes in aCD packing at guest inclusion is given in Fig. 8.

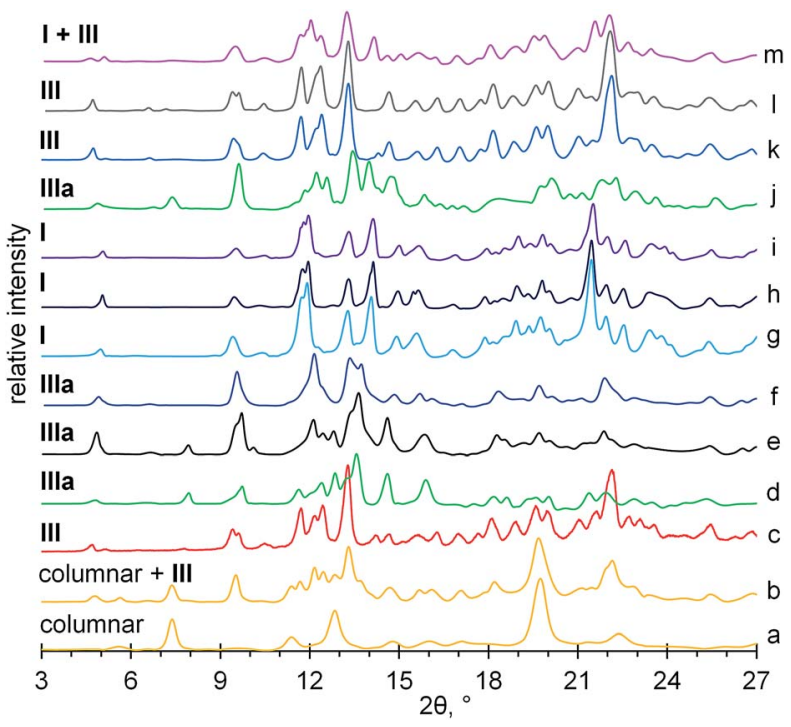

Fig. 7 X-ray powder diffractograms for (a) $\mathrm{aCD} \cdot 1.3\left(\mathrm{CH}_{3}\right)_{2} \mathrm{CO} \cdot 2.7 \mathrm{H}_{2} \mathrm{O}$ clathrate prepared in "aCD hexahydrate + desiccant + guest" system; (b) $\mathrm{aCD} \cdot 1.2\left(\mathrm{CH}_{3}\right)_{2} \mathrm{CO} \cdot 2.3 \mathrm{H}_{2} \mathrm{O}$ from tetrahydrate $\mathrm{A}$; $\quad$ (c) $\mathrm{aCD} \cdot 1.1 \mathrm{EtCN} \cdot 3.6 \mathrm{H}_{2} \mathrm{O}$ prepared in "aCD hexahydrate + desiccant + guest" system; (d) aCD $1.1 n-\mathrm{PrOH} \cdot 3 . \mathrm{H}_{2} \mathrm{O}$ clathrate prepared in "hexahydrate + desiccant + guest" system; (e) anhydrous $\mathrm{CCD}^{\cdot 18}$ (f) tetrahydrate $A$; $(\mathrm{g})$ tetrahydrate $\mathrm{B}$; (h) saturated $\mathrm{CCD}$ hexahydrate, ${ }^{18}$ (i) $\mathrm{aCD} \cdot 0.3 \mathrm{CH}_{2} \mathrm{Cl}_{2} \cdot 4.0 \mathrm{H}_{2} \mathrm{O}$ from tetrahydrate $\mathrm{B}$; (j) aCD $0.9 n-\mathrm{PrOH} \cdot 4.3 \mathrm{H}_{2} \mathrm{O}$ from tetrahydrate $\mathrm{A} ;(\mathrm{k}) \mathrm{aCD} \cdot 0.6 \mathrm{CH}_{3} \mathrm{NO}_{2} \cdot 4.5 \mathrm{H}_{2} \mathrm{O}$ from tetrahydrate $\mathrm{B}$; (l) aCD $5.9 \mathrm{H}_{2} \mathrm{O}$ after equilibration with $\mathrm{CH}_{3} \mathrm{NO}_{2}$ vapor; $(\mathrm{m}) \mathrm{aCD} \cdot 5.9 \mathrm{H}_{2} \mathrm{O}$ after equilibration with EtCN vapor.
According to the PXRD data, Fig. 7, ESI, $\uparrow$ the most significant transformations of crystal packing upon guest inclusion were observed for aCD hexahydrate in the presence of desiccant. The guest inclusion in these systems changes the initial cage-type pattern of saturated aCD hexahydrate described as Form $\mathrm{I}^{40}$ to three different packing patterns, Fig. 8. Clathrate formation with propionitrile and dichloromethane gives Form III, Fig. 7c, ESI, $\uparrow$ which was previously observed for aCD $\cdot 7.57 \mathrm{H}_{2} \mathrm{O}$ hydrate ${ }^{41}$ and for some ternary aCD clathrates with organic guests crystallized from aqueous solutions. ${ }^{42-44}$ Inclusion of 1-propanol by hexahydrate with desiccant gives Form IIIa, Fig. 7d, which has the same diffraction pattern as the anhydrous $\mathrm{aCD},{ }^{18}$ Fig. 7e. The indexing of Form IIIa diffractogram gives a cell with the volume $3787.41 \AA^{3}$, Table 3, which is smaller than that of Form III $\left(5065.62 \AA^{3}\right)^{40}$ but has the same orthorhombic space group $P 2_{1} 2_{1} 2_{1}$, ESI. $\dagger$ Diffractogram of acetone clathrate prepared under the same conditions, Fig. 7a, corresponds to the hexagonal packing of columnar phase, which was prepared elsewhere by precipitation from aqueous solution of aCD with poly(ethylene glycol $)^{45}$ and from a mixture of chloroform with aqueous solution of aCD. ${ }^{46}$

For comparison, the equilibration with guest vapors of $\mathrm{aCD} \cdot 5.9 \mathrm{H}_{2} \mathrm{O}$ (Form I) without desiccant results in the most cases only in a partial transformation to Form III, Fig. 8, ESI. $\dagger$ Saturation of this hexahydrate with vapors of dichloromethane, propionitrile, 1-propanol and acetone gives mixtures of Form I and III, Fig. $7 \mathrm{~m}$ and 8, ESI. $\dagger$ Dichloromethane and propionitrile are capable of this transformation even at their negligibly small

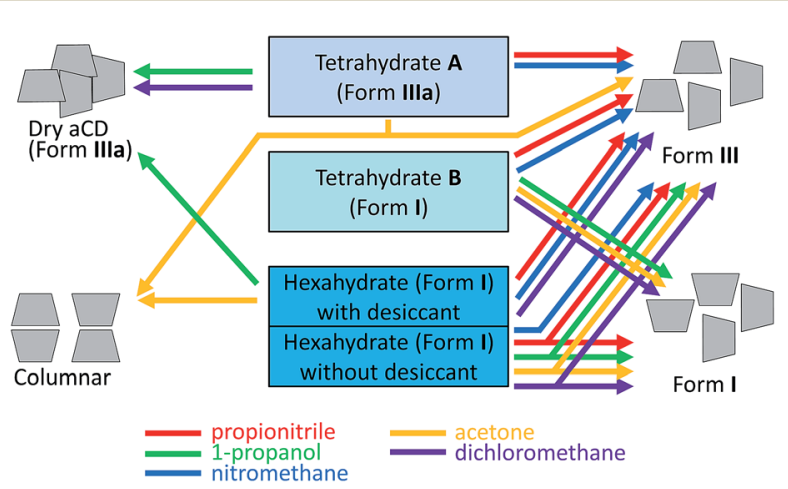

Fig. 8 Schematic presentation of aCD crystal packing types prepared by saturation of $\mathrm{aCD}$ hydrates with various guest vapors (colored arrows). The branched arrows indicate the mixture of two packing forms. Included guests are not shown in schematic packings. 
inclusion (less than $0.1 \mathrm{~mol}$ per mol aCD). Methanol and ethanol, which inclusion is less affected by the guest-water competition, Table 1, completely transform the initial Form I of $\mathrm{aCD} \cdot 5.9 \mathrm{H}_{2} \mathrm{O}$ to the Form III, ESI. $\dagger$ The product of aCD $\cdot 5.9 \mathrm{H}_{2} \mathrm{O}$ equilibration with nitromethane vapor has the packing of Form III, Fig. 7l, despite there is no nitromethane inclusion and hydration decrease, ESI. $\dagger$

The PXRD data exhibit an influence of hydration history on the packing of aCD tetrahydrates. Both A and B forms have packings close to that of the initial states, from which they were prepared. The diffractogram of tetrahydrate A has the same characteristic peaks as the anhydrous aCD (Form IIIa), Fig. 7e and $f$. The diffraction pattern of tetrahydrate $B$ is that of aCD $5.9 \mathrm{H}_{2} \mathrm{O}$ (Form I), Fig. $7 \mathrm{~g}$ and h. These different PXRD patterns of $\mathrm{A}$ and $\mathrm{B}$ tetrahydrates may be a result of crystal cooperativity keeping packing patterns unchanged at partial hydration and dehydration, respectively.

In the most studied cases, the observed hydration/ dehydration hysteresis for the packings of tetrahydrates A and $B$ has an effect on the PXRD patterns of their inclusion compounds with the studied guests. The initial patterns of these tetrahydrates remain unchanged upon inclusion of dichloromethane and 1-propanol by A (Form IIIa) and upon inclusion of acetone, dichloromethane and 1-propanol by $\mathrm{B}$ (Form I), Fig. 7j, i and 8, ESI. $\dagger$ The inclusion of acetone by A changes its packing to the mixture of columnar and III forms, Fig. 7b. Both tetrahydrates include propionitrile and nitromethane producing the same packing III, despite their different inclusion capacities for nitromethane, Fig. 7k, 8 and Table 2, ESI. $\uparrow$ So, in the most studied cases, the hydration history affects the inclusion capacity of aCD by switch of its packing both in the states of initial hydrate and final host-guest clathrate.

In this smart control, the change of the initial packing of aCD hydrate shifts the optimal hydration in different extent for different guests. Hence, each studied guest has its own specific hydration history effect for inclusion by aCD, Table 2 and Fig. 8. Besides, the direction of hydration change in the used hydrate preparation procedures should have an influence on the energy of water molecules in the aCD phase, which is important for guest inclusion by cyclodextrins. ${ }^{47,48}$ The tetrahydrate A with a higher inclusion capacity may be less stable than B because 4 water molecules included by anhydrous aCD with formation of A do not change its packing, Fig. 7e and $\mathrm{f}$, and the cell volume, which is less by $27 \%$ than that of B, Fig. 8 and Table 3 . Respectively, in the most studied cases, the guest inclusion by $\mathrm{A}$ gives much larger cell expansion per 1 aCD molecule than the inclusion by B, Fig. 8 and Table 3. So, the configurations of water $\mathrm{H}$-bonds in A may be not optimal, and its hydration water may be regarded as having "high energy", and its exchange with an organic guest should be easier. This is confirmed by the lower water contents of inclusion compounds prepared from A where this tetrahydrate includes more organic guest than $\mathrm{B}$, Table 2. Respectively, water molecules in tetrahydrate B formed by dehydration may be regarded as having "low energy". So, the widely used explanation of the guest inclusion by cyclodextrins as activated by "high-energy" water, ${ }^{\mathbf{4 8}}$ has now an alternative experimental justification.
The hydration history effect on the state of water in tetrahydrates A and B and in inclusion compounds prepared from them was characterized also in kinetic experiments for their thermal decomposition. For this, TG curves at heating rates of 5,10 and $20 \mathrm{~K} \mathrm{~min}^{-1}$ were determined for tetrahydrates $\mathrm{A}$ and $\mathrm{B}$ and for inclusion compounds aCD-0.9EtCN $\cdot 3.8 \mathrm{H}_{2} \mathrm{O}$ and $\mathrm{aCD} \cdot 1.0 \mathrm{EtCN} \cdot 4.1 \mathrm{H}_{2} \mathrm{O}$ prepared by saturation of $\mathrm{A}$ and $\mathrm{B}$, respectively, with propionitrile vapors. The choice of these inclusion compounds was defined by the higher separation of dehydration and guest release steps observed in their TG/MS curves at heating rate of $10 \mathrm{~K} \mathrm{~min}^{-1}$, ESI. $\dagger$ Besides, these two inclusion compounds have the same water contents, which makes more comparable their kinetic parameters of dehydration. The data of kinetic experiment and results of its approximation with model-free kinetic equations and optimal kinetic models for the studied hydrates and inclusion compounds are given in ESI. $\uparrow$ The activation energies of dehydration and guest release $E_{\mathrm{a}}$ are given in Table 4 . For comparison, the enthalpies of dehydration $\Delta H_{\text {dehydr }}$ and guest release $\Delta H_{\mathrm{e}}$ calculated from simultaneous TG/DSC/MS data, ${ }^{18}$ ESI, $\dagger$ are given in Table 4.

Comparison of the activation energies $E_{\mathrm{a}}$ of dehydration determined exhibits an essential difference between water properties in A and B having different histories of hydration, Table 4. Tetrahydrate A has the higher value of $E_{\mathrm{a}}=79 \mathrm{~kJ} \mathrm{~mol}^{-1}$ than $\mathrm{B}\left(E_{\mathrm{a}}=52 \mathrm{~kJ} \mathrm{~mol}^{-1}\right)$ despite A is supposed above to have the relatively "high-energy" water in the above comparison of its inclusion properties with those of $\mathrm{B}$. The last value is close to dehydration enthalpy of these hydrates, $\Delta H_{\text {dehydr }}$, which is practically the same for A and B: $48 \mathrm{~kJ} \mathrm{~mol}^{-1}$, Table 4 .

The observed difference in $E_{\mathrm{a}}$ values of dehydration for the studied tetrahydrates becomes below the level of experimental errors when these hydrates include propionitrile: $E_{\mathrm{a}}=$ $66 \mathrm{~kJ} \mathrm{~mol}^{-1}$ for aCD $0.9 \mathrm{EtCN} \cdot 3.8 \mathrm{H}_{2} \mathrm{O}$ (from A) and $E_{\mathrm{a}}=$ $58 \mathrm{~kJ} \mathrm{~mol}^{-1}$ for aCD $1.0 \mathrm{EtCN} \cdot 4.1 \mathrm{H}_{2} \mathrm{O}$ (from $\mathrm{B}$ ). These data are in agreement with dehydration enthalpy $\Delta H_{\text {dehydr }}$ of these inclusion compounds, which is equal to 58 and $61 \mathrm{~kJ} \mathrm{~mol}^{-1}$, respectively, Table 4 . For comparison, the activation energies of dehydration for saturated hydrates of $\beta C D$ and $\gamma C D$ are equal to 65 and $58 \mathrm{~kJ} \mathrm{~mol}^{-1}$, respectively. ${ }^{49,50}$ Kinetic parameters of EtCN release from the studied inclusion compounds are less defined because Friedman and Ozawa-Flynn-Wall "model-free" methods indicate a significant variation of $E_{\mathrm{a}}$ at the change of conversion extent, Table 4, ESI, $\dagger$ which indicates a complex process of guest elimination. In both cases, the $E_{\mathrm{a}}$ values are in the range above $90 \mathrm{~kJ} \mathrm{~mol}^{-1}$ being in agreement with high activation energies observed for elimination of ethyl benzoate ${ }^{51}$ and benzaldehyde ${ }^{52}$ from inclusion compounds with bCD.

The significant influence of hydration history on kinetics of dehydration observed for tetrahydrates A and B may be explained by their different densities estimated from the cell volumes, Table 3. Tetrahydrate A has the higher activation energy of dehydration, Table 4, probably because its packing (Form IIIa) has a more compact cell than that of tetrahydrate B (Form I) according to their volumes per 1 aCD molecule, Table 3. So, water molecules need to overcome a higher energy barrier to leave the denser packing of A. If these molecules are 
Table 4 Enthalpies and activation energies of thermal decomposition for tetrahydrates A and B with different hydration histories and for their inclusion compounds with propionitrile

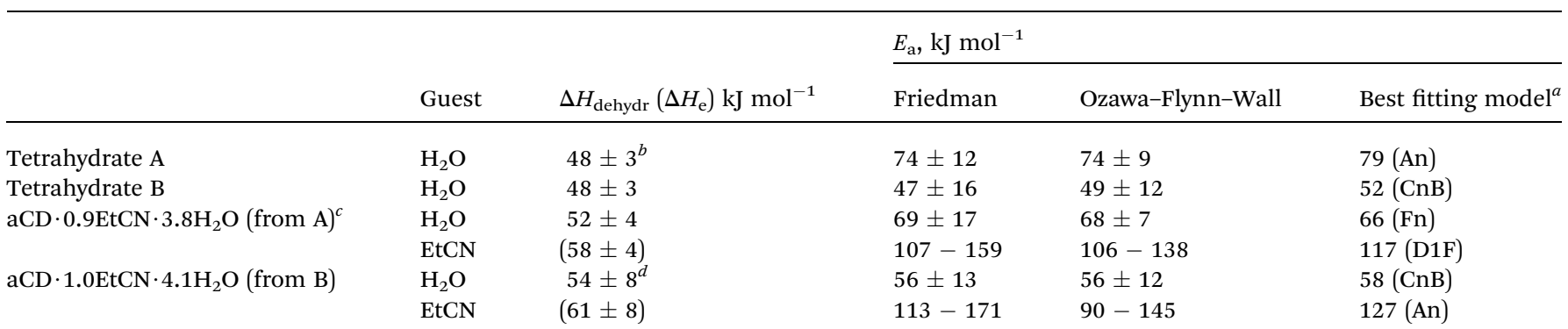

${ }^{a}$ Kinetic model codes: An - Avrami-Erofeev $n$-dimensional nucleation, $\mathrm{CnB}$ - reaction of $n^{\text {th }}$ order with autocatalysis by product, Fn - reaction of $n^{\text {th }}$ order, D1F - one-dimensional diffusion by Fick's law. More detailed kinetic parameters are given in ESI. ${ }^{b}$ Data from ref. $18 .{ }^{c}$ Inclusion compound loses water in the first step and propionitrile in the second step of thermal decomposition. ${ }^{d}$ Dehydration is overlapped partially by EtCN release, and $\Delta H_{\text {dehydr }}$ is calculated by subtracting the contribution of EtCN in the first step according to the MS curves for this guest and water, ESI.

eliminated from the inside of aCD molecular cavity, they will be also of relatively "high energy".

The observed correlation between guest inclusion capacity of aCD hydrates and their packing at the same hydration reached by different hydration paths may be used to explain the activating role of water in the interaction of hydrophobic substrates with the other solid hydrophilic receptors, like proteins, for which PXRD method gives much less information on the structural changes upon hydration/dehydration. ${ }^{53}$ The idea to draw an analogy between the hydration effects on receptor properties of cyclodextrins and proteins was proposed elsewhere. ${ }^{19}$ Both for cyclodextrins ${ }^{48}$ and proteins, ${ }^{54}$ the same concept of "high-energy" water was offered as having not optimal configuration of $\mathrm{H}$-bonds in receptor phase, which conformational stress is released upon guest (substrate) inclusion with the corresponding energy gain. The hydration history effect for enzymatic activity under low-water conditions observed elsewhere ${ }^{22}$ may have the same structural causes as the hydration history influence on aCD inclusion capacity found in the present work.

\section{Conclusions}

Hydration history effect helps to control the guest inclusion by $\alpha$-cyclodextrin (aCD) and reveals the water role in this process. Depending on the hydration/dehydration order and extent, the inclusion capacity of this cyclodextrin for organic guests may be switched on/off or changed significantly. The variation in the aCD hydration/dehydration procedures correlates with the observed changes in crystal packing of the prepared aCD hydrates, which provides a structural basis for hydration history effect.

Depending on direction of aCD hydration change in the final step of the hydrate preparation procedure, the aCD hydrate may have a higher or lower guest inclusion capacity, a higher or lower expansion of its crystallographic cell volume at the guest inclusion, a higher or lower activation energy of dehydration, a higher or lower ability to exchange water for organic guest. This helps to qualify the hydration water of aCD as being of "high-energy" or "low-energy", and, respectively, to have an activating or competing role in guest inclusion. These results are relevant for optimization of guest inclusion by aCD, which drags behind the other cyclodextrins in practical applications, and for comprehension of hydration effects in biological processes where interaction of hydrated hydrophilic receptors with hydrophobic substrates is a normal phenomenon.

\section{Conflicts of interest}

There are no conflicts to declare.

\section{Acknowledgements}

The work was supported by Russian Government Program of Competitive Growth of Kazan Federal University and by RFBR, grant No. 18-33-00056. The equipment of Federal Centre of Shared Equipment of Kazan Federal University was used in this work.

\section{Notes and references}

1 G. Crini, Chem. Rev., 2014, 114, 10940-10975.

2 L. Szente and J. Szejtli, Trends Food Sci. Technol., 2004, 15, 137-142.

3 P. Jansook, N. Ogawa and T. Loftsson, Int. J. Pharm., 2018, 535, 272-284.

4 J. Køhler, C. Schönbeck, P. Westh and R. Holm, J. Phys. Chem. B, 2016, 120, 396-405.

5 N. Ogawa, C. Takahashi and H. Yamamoto, J. Pharm. Sci., 2015, 104, 942-954.

6 E. Specogna, K. W. Li, M. Djabourov, F. Carn and K. Bouchemal, J. Phys. Chem. B, 2015, 119, 1433-1442.

7 F. Giordano, A. Gazzaniga, G. P. Bettinetti and A. La Manna, Int. J. Pharm., 1990, 62, 153-156.

8 V. V. Gorbatchuk, A. K. Gatiatulin, M. A. Ziganshin, A. T. Gubaidullin and L. S. Yakimova, J. Phys. Chem. B, 2013, 117, 14544-14556.

9 A. Wongmekiat, Y. Tozuka, T. Oguchi and K. Yamamoto, Int. J. Pharm., 2003, 265, 85-93. 
10 P. A. Ponce Cevallos, M. P. Buera and B. E. Elizalde, J. Food Eng., 2010, 99, 70-75.

11 N. Mennini, M. Bragagni, F. Maestrelli and P. Mura, J. Pharm. Biomed. Anal., 2014, 89, 142-149.

12 M. R. Serafini, P. P. Menezes, L. P. Costa, C. M. Lima, L. J. Quintans, J. C. Cardoso, J. R. Matos, J. L. SoaresSobrinho, S. Grangeiro, P. S. Nunes, L. R. Bonjadim and A. A. S. Araújo, J. Therm. Anal. Calorim., 2012, 109, 951-955.

13 C. J. Zhou, L. F. Li, Y. Liu, S. P. Wen, Y. E. Guo and X. G. Niu, Adv. Mater. Res., 2012, 455-456, 1177-1181.

14 F. G. Gu, Y. Wang, G. D. L. Meng, H. B. Han and C. Z. Wu, Pharmazie, 2012, 67, 143-146.

15 R. Shapira, Y. S. Balazs, S. Kababya, R. Edrei and Y. Eichen, Phys. Chem. Chem. Phys., 2018, 20, 29610-29615.

16 H. Yoshii, T. Furuta, E. Okita, A. Toyomi, Y.-Y. Linko and P. Linko, Biosci., Biotechnol., Biochem., 1998, 62, 464-468.

17 M. R. Caira, D. R. Dodds and L. R. Nassimbeni, J. Therm. Anal. Calorim., 2002, 68, 647-655.

18 A. K. Gatiatulin, V. Y. Osel'skaya, M. A. Ziganshin and V. V. Gorbatchuk, Phys. Chem. Chem. Phys., 2018, 20, 26105-26116.

19 A. K. Gatiatulin, M. A. Ziganshin, G. F. Yumaeva, A. T. Gubaidullin, K. Suwińska and V. V. Gorbatchuk, $R S C$ Adv., 2016, 6, 61984-61995.

20 H. Yoshii, T. Furuta, A. Yasunishi and H. Hirano, J. Biochem., 1994, 115, 1035-1037.

21 Y. Nakai, Y. Keiji, T. Katsuhide, K. Atsushi and S. Isao, Chem. Pharm. Bull., 1986, 34, 2178-2182.

22 P. J. Halling, Philos. Trans. R. Soc., B, 2004, 359, 1287-1297.

23 N. Morohashi and T. Hattori, J. Inclusion Phenom. Macrocyclic Chem., 2018, 90, 261-277.

24 A. V. Yakimov, M. A. Ziganshin, A. T. Gubaidullin and V. V. Gorbatchuk, Org. Biomol. Chem., 2008, 6, 982-985.

25 G.-F. Yang, H.-B. Wang, W.-C. Yang, D. Gao and C.-G. Zhan, J. Phys. Chem. B, 2006, 110, 7044-7048.

26 S. Pereva, T. Sarafska, S. Bogdanova and T. Spassov, J. Drug Delivery Sci. Technol., 2016, 35, 34-39.

27 N. M. Patro, A. Sultana, K. Terao, D. Nakata, A. Jo, A. Urano, Y. Ishida, R. N. Gorantla, V. Pandit, K. Devi, S. Rohit, B. K. Grewal, E. M. Sophia, A. Suresh, V. K. Ekbote and S. Suresh, J. Inclusion Phenom. Macrocyclic Chem., 2014, 78, 471-483.

28 S. V. Kurkov and T. Loftsson, Int. J. Pharm., 2013, 453, 167180.

29 B. R. Bhandari, B. R. D'Arc and L. Le Thi Bich, J. Agric. Food Chem., 1998, 46, 1494-1499.

30 V. Nekkanti, T. Muniyappan, P. Karatgi, M. S. Hari, S. Marella and R. Pillai, Drug Dev. Ind. Pharm., 2009, 35, 1219-1229.

31 V. V. Gorbatchuk, A. K. Gatiatulin and M. A. Ziganshin, in Comprehensive Supramolecular Chemistry II, ed. J. L. Atwood, G. W. Gokel and L. J. Barbour, Elsevier, Oxford, 2017 , ch. 2.07 , vol. 2 , pp. 139-150.
32 V. V. Gorbatchuk, N. A. Mironov, B. N. Solomonov and W. D. Habicher, Biomacromolecules, 2004, 5, 1615-1623.

33 L. S. Yakimova, M. A. Ziganshin, V. A. Sidorov, V. V. Kovalev, E. A. Shokova, V. A. Tafeenko and V. V. Gorbatchuk, J. Phys. Chem. B, 2008, 112, 15569-15575.

34 H. L. Friedman, J. Polym. Sci., Part C: Polym. Symp., 1964, 6, 183-195.

35 T. Ozawa, Thermochim. Acta, 1992, 203, 159-165.

36 J. H. Flynn and L. A. Wall, J. Res. Natl. Bur. Stand., Sect. A, 1966, 70, 487-523.

37 S. Vyazovkin, K. Chrissa, M. Laura, D. Lorenzo, N. Koga, M. Pijolat, B. Roduit, N. Sbirrazzuoli and J. Josep, Thermochim. Acta, 2014, 590, 1-23.

38 V. V. Gorbatchuk, A. G. Tsifarkin, I. S. Antipin, B. N. Solomonov, A. I. Konovalov, J. Seidel and F. Baitalov, J. Chem. Soc., Perkin Trans. 2, 2000, 2287-2294.

39 V. V. Gorbatchuk, M. A. Ziganshin and B. N. Solomonov, Biophys. Chem., 1999, 81, 107-123.

40 P. C. Manor and W. Saenger, J. Am. Chem. Soc., 1974, 96, 3630-3639.

41 K. K. Chacko and W. Saenger, J. Am. Chem. Soc., 1981, 103, 1708-1715.

42 T. Nakagawa, S. Immel, F. W. Lichtenthaler and H. J. Lindner, Carbohydr. Res., 2000, 324, 141-146.

43 B. Hingerty and W. Saenger, J. Am. Chem. Soc., 1976, 98, 3357-3365.

44 J. Storsberg, H. Ritter, H. Pielartzik and L. Groenendaal, Adv. Mater., 2000, 12, 567-569.

45 I. N. Topchieva, A. E. Tonelli, I. G. Panova, E. V Matuchina, F. a Kalashnikov, V. I. Gerasimov, C. C. Rusa, M. Rusa and M. a Hunt, Langmuir, 2004, 20, 9036-9043.

46 C. C. Rusa, T. a Bullions, J. Fox, F. E. Porbeni, X. Wang and A. E. Tonelli, Langmuir, 2002, 18, 10016-10023.

47 S. Angelova, V. Nikolova, S. Pereva, T. Spassov and T. Dudev, J. Phys. Chem. B, 2017, 121, 9260-9267.

48 W. Saenger, M. Noltemeyer, P. C. Manor, B. Hingerty and B. Klar, Bioorg. Chem., 1976, 5, 187-195.

49 A. Szafranek, J. Therm. Anal., 1988, 34, 917-926.

50 E. M. M. R. Caira and S. A. Bourne, J. Therm. Anal. Calorim., 1999, 56, 1329-1334.

51 G. E. Zhang, X. T. Li, S. J. Tian, J. H. Li, J. Y. Wang, X. D. Lou and Q. T. Cheng, J. Therm. Anal. Calorim., 1998, 54, 947-956.

52 S. J. Tian, G. X. Xi, Q. T. Cheng, X. D. Lou and J. H. Li, J. Therm. Anal. Calorim., 1998, 53, 825-833.

53 R. B. Gregory, Protein Hydration and Glass Transition Behavior, in Protein-Solvent Interactions, ed. R. B. Gregory, Marcel Dekker, New York, 1995, pp. 217-221.

54 S.-H. Chen and M.-C. Bellissent-Funel, Structure and Dynamics of Water in Confined Geometry, in Hydrogen Bond Networks, ed. M. C. Bellissent-Funel and J. C. Dore, Springer-Science+Business Media, Dordrecht, 1994, pp. 307-337. 